\title{
Exergy analysis of a flat plate solar collector with latent heat storage by phase change material for water heating applications at low temperature
}

\author{
* Angie Rincon Ortega', Dr. Mauricio Carmona ${ }^{2}$ \\ 1, 2 Mechanical Engineering Department, Universidad del Norte, Barranquilla, Colombia \\ 1 E mail: anggier@uninorte.edu.co ,2E mail: mycarmona@uninorte.edu.co
}

\begin{tabular}{l}
\hline A R T I C L E I N F 0: \\
\hline Article history: \\
Received 2 August 2017 \\
Accepted 27 August 2017 \\
Available online 12 October \\
2017 \\
\hline Keywords: \\
Thermal energy \\
storage; \\
Phase change \\
material; \\
Exergy analysis; \\
Flat plate solar \\
collector.
\end{tabular}

This work is licensed under a Creative Commons Attribution NonCommercial - NoDerivs 4.0. "CC-BY-NC-ND"

\begin{abstract}
A B S T R A C T
An exergy analysis has been performed to determine the potential for useful work in a latent heat storage system with phase change material (PCM) for a flat-plate solar collector. Commercial paraffin wax is used as PCM to store and release energy in the solid-liquid transformation; this material is located in metal containers under the absorber plate on the bottom insulation of the collector. The exergy analysis is performed in outdoor conditions for days of low, medium and high radiation taken from October 2016 to March 2017 at Barranquilla city (latitude: $10^{\circ} 59^{\prime} 16^{\prime \prime} \mathrm{N}$, longitude: $74^{\circ} 47^{\prime} 20^{\prime \prime} \mathrm{O}$, Colombia). The system is evaluated throughout charge and discharge periods. The energy and exergy balance equations based on the first and second law of thermodynamics is formulated and solved for each element of the collector system as well as for the PCM. Results obtained show the energy distribution and energetic destruction for each system component and its variation as a time function. It was observed that the average energy and energetic efficiency are $28.7 \%, 13.2 \%$ for of low radiation days. 26.9\%, 20.56\% for of medium radiation days, and $23.2 \%, 18.6 \%$ for of high radiation days, respectively. Results of the analysis are shown in detail in the present paper. JOURNAL OF CONTEMPORARY URBAN AFFAIRS (2017) 1(3), 43-48. https://doi.org/10.25034/ijcua.2018.3678

www.ijcua.com

Copyright (C) 2017 Journal Of Contemporary Urban Affairs. All rights reserved
\end{abstract}

\section{Introduction}

In recent years there is a grown interest in the use of renewable energy due to the scarcity of fossil energy reserves and the environmental impact caused by their management. Among renewable energy sources solar energy has been great attention due to the ease of obtaining and high potentiality in the generation of electricity and heat, the use of solar heating systems has increased on the basis of reasonable initial costs and structure relatively simple (Jafarkazemi, and Ahmadifard, 2013). For any application with solar thermal systems solar collectors constitute an important component, their operation is based on the capture of the radiation coming from the sun, converting it to heat and the transfer of this heat to a circulating fluid through the collector. The collected energy is carried by the fluid directly to a process requiring heat or to a thermal energy storage system and subsequently withdrawn for use (Kalogirou, 2004). There are different forms of storing thermal energy, among them are the storage by sensible heat, by the

\section{*Corresponding Author:}

Mechanical Engineering Department, Universidad del Norte,

Barranquilla, Colombia

E-mail address: anggier@uninorte.edu.co 
thermochemical reaction and by latent heat (Oliver et al., 2010).

The most common forms used are by sensible heat and latent heat. Energy stored in the form of sensible heat requires a large volume of the material used to store, while latent heat storage such as phase change materials (PCM) provides higher storage density and little temperature variation during phase change. Techniques have been investigated to improve the thermal energy storage performance with the use of phase change materials, in addition to improving the heat transfer with the application of fins and to improve the thermal conductivity with the PCM encapsulation (Nkwetta, and Haghighat, 2014). Thermal performance can be assessed based on the first thermodynamics law of (Energy Conservation) or the second thermodynamics law of (Principle exergy).

The work done by $(\mathrm{Li}, 2015)$ shows the review of several techniques to improve energy and exergetic performance. In addition, it concludes that the evaluation of the energetic efficiency is not enough to evaluate the thermal behavior of storage. The weakness of thermodynamics first law analysis is it does not take into account the quality of energy degradation when the energy is converted from one form to another or is exchanged between materials and the currents along of heat transfer processes (Kalogirou et al., 2016). In this context, the second thermodynamics law evaluates the quality energy, and the first law focuses on amount energy. Meanwhile, the exergetic analysis

uses the mass conservation and energy principles with the second thermodynamics law, for to design and to analyze energetic systems (Kocca et al., 2007).

In a solar system, energy inlet is solar energy, (Petela, 1964) in his works exposed the formulas for to calculate the exergy of thermal radiation. And presented a discussion of the dependence of exergy of fluid and the radiation on the temperature. On the other hand, the investigations presented by (Kalogirou et al., 2016) are based on basic principles of exergy analysis and show a review of the thermal analysis of solar collectors and the processes to involving collectors as an energy source. (Jafarkazemi, and Ahmadifard, 2013). They performed a theoretical model and experimental validation for the energetic and exergetic analysis for flat-plate solar collectors, finding the effect of different design parameters in the efficiencies for to determine the optimum working condition.
The main purpose of this study is to perform an exergetic analysis for a flat-plate solar collector with thermal storage system with phase change material. It was determined the exergetic efficiency and exergy destruction for each system component and its variation as a time function for days of low, medium and high radiation.

\section{Method and materials}

In this study, experimental setup consists of a latent heat storage system with phase change material (PCM) for a flat-plate solar collector as shown in Figure 1 wherein its components are listed. Commercial paraffin wax is used as PCM; this material is located in metal containers under the absorber plate on the bottom insulation of the collector. Measurement of collector system temperatures was with thermocouples, located in glass cover, absorber plate and inlet and outlet water in the copper pipe. The energy and exergy performance of the system was analyzed during days of low, medium and high radiation taken from October 2016 to March 2017 in Barranquilla Atlántico. Initially, for to do energy and exergy analysis, inlet and outlet parameters to heat transfer of each component of the system was specified. Figure 1 shows heat transfer terms involved in the solar collector.

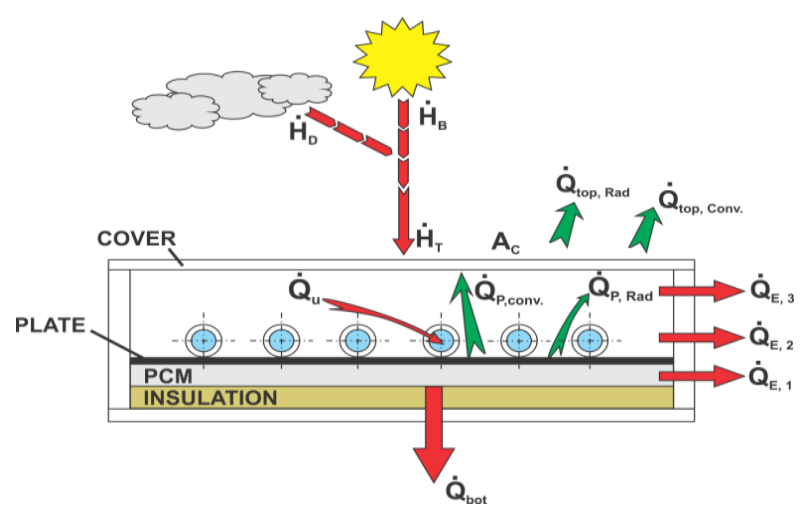

Figure 1. Heat transfer terms involved in solar collector.

The notations and diagrams of the references (Asbik et al., 2016) and (Faramarz Sarhaddi, 2016), was used. In Figure 2. shown the exergy of heat associated with the radiation heat transfer, convection, and conduction in each component of the device. Equations were obtained expressing the exergy destroyed in the glass cover, absorber plate, and the PCM container during charge and discharge of system associates with the heat transfer of exergy equation (Moran and Shapiro, 2004) (1). $E x_{q}=Q\left(1-\frac{T_{a}}{T}\right)$ 
The exergetic efficiency is given by equation (2), which relates the input solar radiation exergy and the exergy transferred to water.

$n_{E x}=\frac{E x_{\text {out }}}{E x_{\text {in }}}$

In Figure 2. 2a shows that the glass cover absorbs a part of solar exergy and transfers to the environment by convection. $2 \mathrm{~b}$. It shows the absorber plate taking into account the charge and discharge processes, during charge process the plate receives solar exergy, transfers by conduction to the PCM and by convection to the water and the glass cover, and during the discharge process receives through the PCM. 2c. It shows the phase change material, during the charge it receives from the absorber plate, during discharge is transferred from the material to the absorber plate to heat the water.

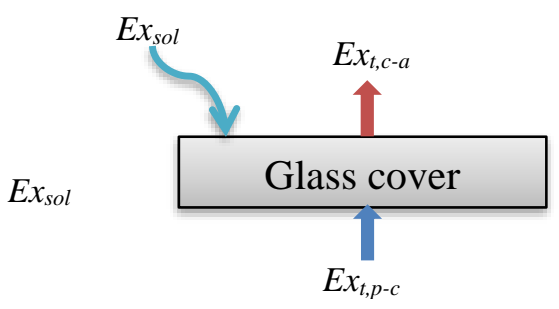

a. Exergy balance of glass cover
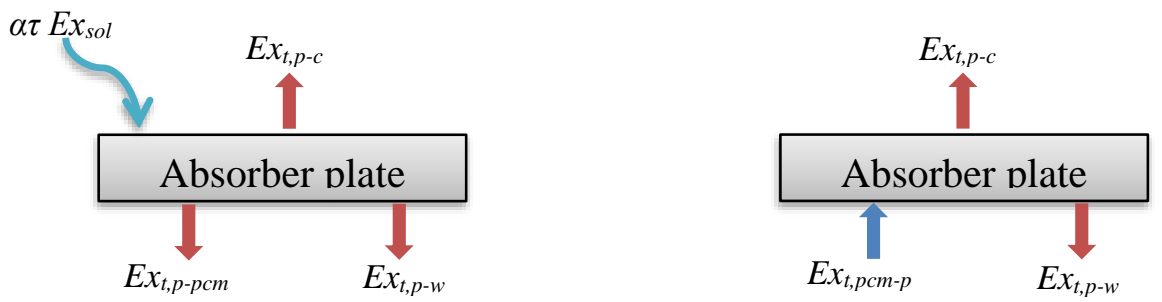

b. Exergy balance of absorber plate (charge/discharge)
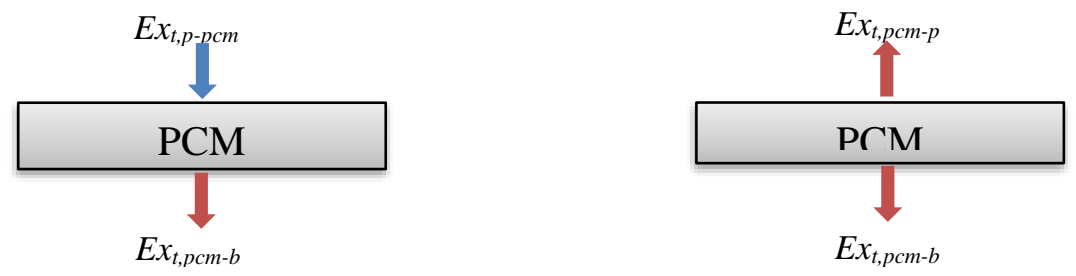

c. Exergy balance of PCM (charge/discharge)

Figure 2. Exergy balance of the solar collector components.

\section{Results and discussion}

In this section, a comparison the performance of a flat plate solar collector with latent heat storage system with phase change material is carried for days of low, medium and high radiation, for that energetic and exergetic efficiency was calculated. The following figures show solar radiation, stored energy and destroyed exergy for each component and the ambient temperature, water outlet temperature, PCM1 and PCM 2 temperatures. The stored energy for different dates between 8:00 and 20:00 hours for every day is shown in Figure 3. In $3 a$ for the glass cover and $3 b$ for the absorber plate. The results of stored energy show similar variation to the solar radiation during the day.

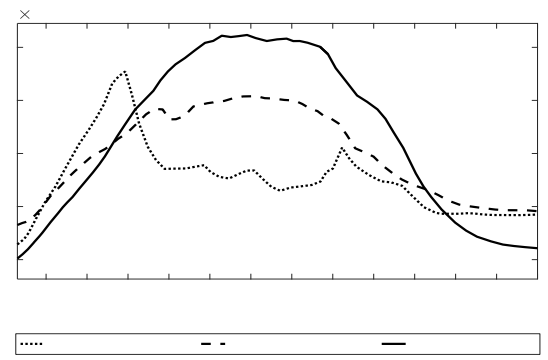

a. Stored energy on glass cover

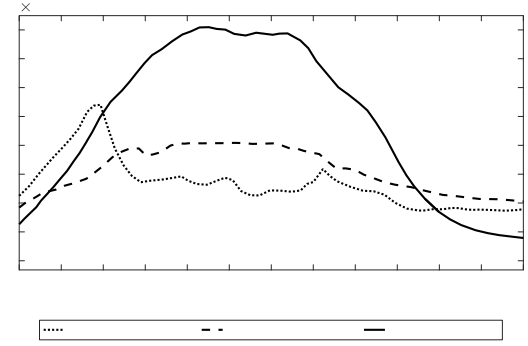

b. Stored energy on absorber plate

Figure 3. Stored energy on glass cover and absorber plate. 
Another hand, the figures $4 a, 5 a, 6 a$ show the accumulated radiation during November 28, 2016, December 16, 2016, and February 07, 2017 consecutively. Given that the exergy associate with the heat transfer is depending on

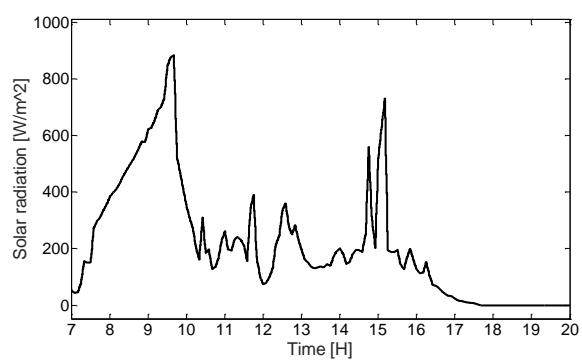

a. Solar radiation for low radiation day

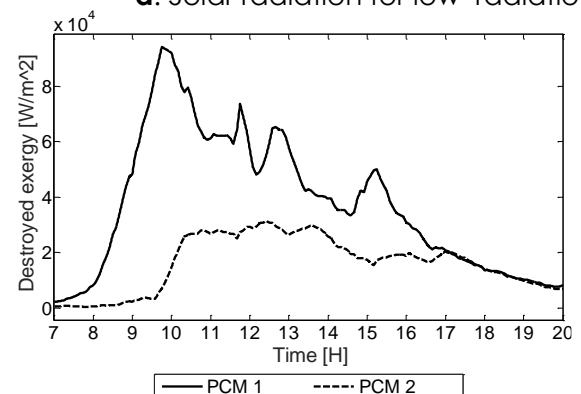

c. Destroyed exergy in PCMl and PCM 2

Figure 4. Results for November 28, 2016: a. Solar radiation, b. Destroyed exergy in glass cover and absorber plate,c. Destroyed exergy in PCM1 and PCM 2, d. Temperatures

The PCM1 and PCM2 layers temperatures illustrated in figures $4 d, 5 d, 6 d$, indicate the behavior of phase change material during everything day. Approximately from 7:00 hours when upsurges temperature of absorber plate, paraffin layers increases the temperature to reach the melting $\left(T=50^{\circ} \mathrm{C}\right)$. In solid state the PCM stores energy as sensible heat and in the

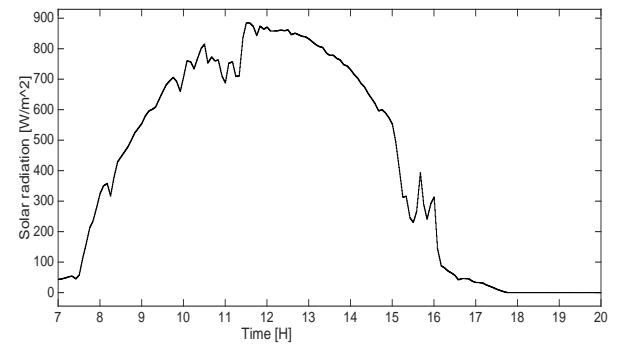

a. Solar radiation for medium radiation day

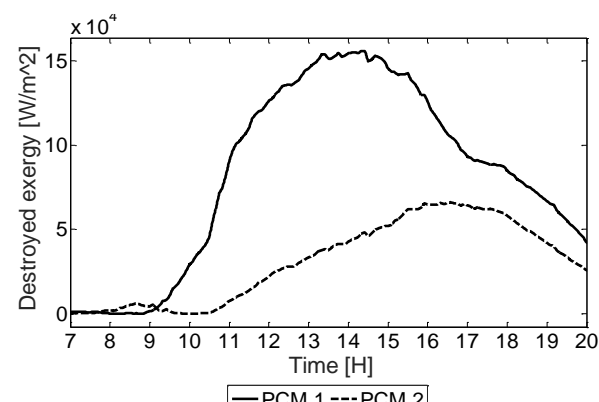

temperatures differences between two elements, and understanding the exergy destruction in each component it is necessary to depict the temperature as a function of time for it.

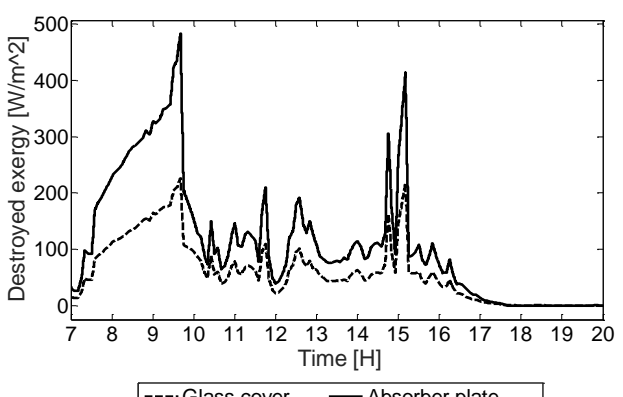

b.Destroyed exergy in glass cover and absorber plate

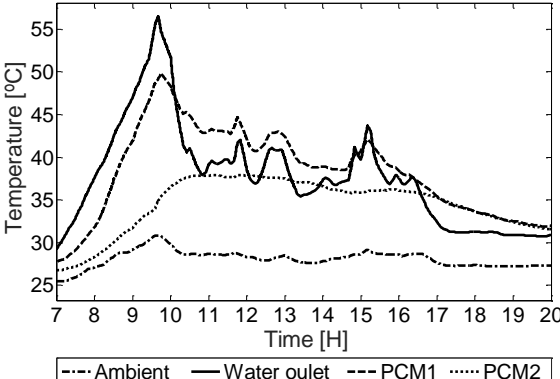

d. Temperatures

liquid phase stores energy as latent heat. As seen in the figures $6 \mathrm{~d}$ on high solar radiation day, the first and second PCM layers reach the fusion temperature at 12:00 hours when there is more radiation on day. Unlike of low and medium solar radiation days (Figure $4 d, 5 d$ ) where PCM does not completely melt.

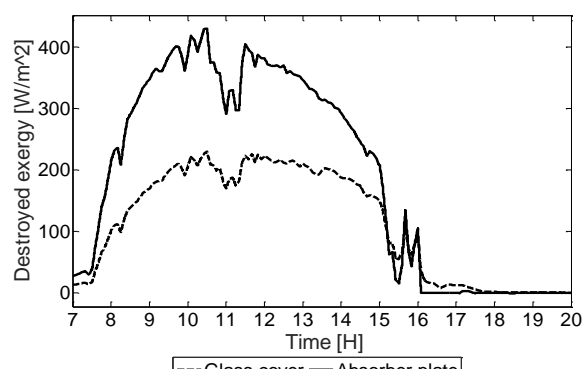

b.Destroyed exergy in glass cover and absorber plate

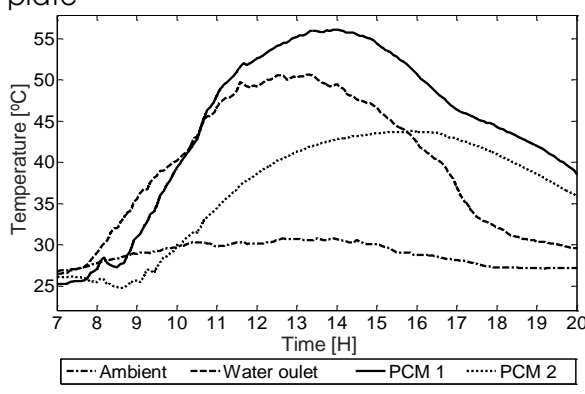



c. Destroyed exergy in PCM1 and PCM 2
d. Temperatures

Figure 5. Results for December 16, 2016: a. Solar radiation, b. Destroyed exergy in glass cover and absorber plate,c. Destroyed exergy in PCM1 and PCM 2, d. Temperatures

The destroyed exergy is calculated by the equation (1). As revealed in figure 6c, the exergy destroyed for the PCM is greater when the first PCM layer is in liquid state, during storage latent heat, and for rest of day, irreversibility is created during the charge of material. However at night some of the exergy is destroyed during PCM discharge, that is some of the exergy transmitted to water at night is destroyed. Similarly, for low and medium solar radiation days (Figure 4c, 5c)

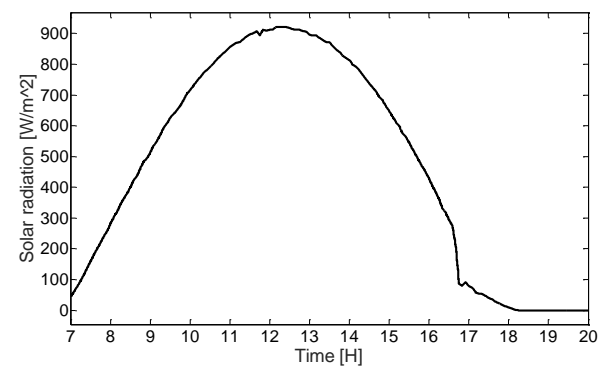

a. Solar radiation for high radiation day

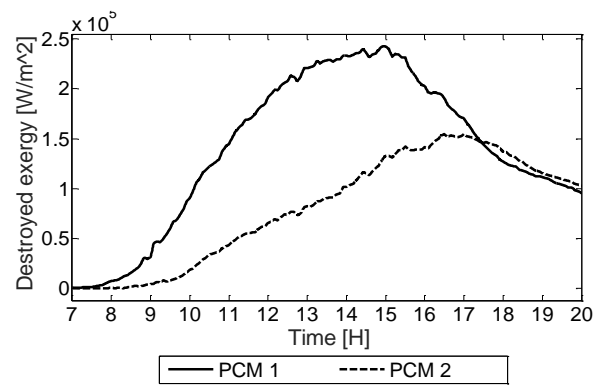

c. Destroyed exergy in PCM1 and PCM 2 the destroyed exergy by PCM is greater when it reaches the highest radiation.

Aditional as shown in figures $4 b, 5 b, 6 c$ the exergy destroyed in the glass cover and absorber plate is superior when there is greater solar radiation. And exergy destruction in absorber plate is greater than in the glass cover because it must transfer heat to water and the PCM during the charge.

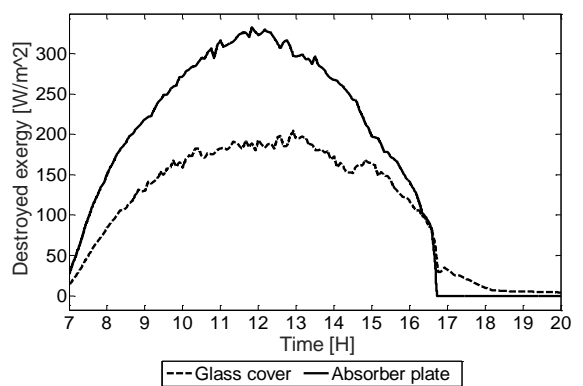

b.Destroyed exergy in glass cover and absorbe plate

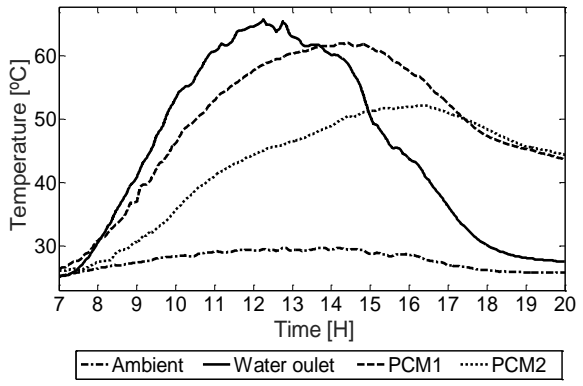

d. Temperatures

Figure 6. Results for February 7, 2017: a. Solar radiation, b. Destroyed exergy in glass cover and absorber plate,c. Destroyed exergy in PCMI and PCM 2, d. Temperatures

The exergetic efficiency is related to heating of water during the night when the storage heat by paraffin is transmitted during phase change. It is calculated by the equation (2). Owing to low radiation on November 28, the PCM did not reach the fusion temperature and the water outlet temperature after 17:00 hours descended approximately ambient temperature, as seen the figure $1 \mathrm{~b}$ resulting to an exergetic efficiency of $11.78 \%$ for low radiation day. On the contrary, in figure $2 \mathrm{~d}$ the water outlet temperature during everything day, is greater between 10:00 and

\section{Conclusions}

The comparison the performance of a flat plate solar collector with latent heat storage using PCM were performed during charge and discharge period on days of low, medium and
15:00 hours when the radiation is higher. But when the sun hides around at 17:00 hours, the water outlet temperature decreases, but still it remains above ambient temperature. Giving an exergetic efficiency of $20.01 \%$ for medium radiation day. On the other hand on March 17 high radiation day, an exergetic efficiency of $28.17 \%$ was obtained. Because to heat recovered at night by the PCM was greater, as seen to figure $3 d$ the water outlet temperature is higher than $60^{\circ} \mathrm{C}$ between at 11:00 and 15:00 hours and stays above during to night.

high radiation. From that experimental study and calculations, some conclusions are as follows:

- There are more stored energy for each component when the solar radiation is higher - The results show that destroyed exergy is relevant in absorber plate and PCM medium during the latent heat storage, so it should be 
minimalized to increase the performance of the system. Nevertheless, during the latent heat storage, the outlet water temperature is increased.

- According to experimental results and calculations obtained, average exergetic efficiency for low radiation day, medium radiation day, and high radiation days was 13.2 $\%, 20.56 \%$, and $18.6 \%$ respectively. That is, the higher efficiency was for medium radiation days, because the high radiation day more exergy is destroyed on each component.

- As a result low oulet water temperature was obtained for low radiation day, but the oulet temperature for medium and hight radiation day was higher, that is, the PCM storage more energy when the radiation is elevated and during night time, heat is transfered to the absorber plate and the water.

The results show that it is necessary to improve some design parameters to reduce the exergy destruction in the PCM and absorber plate, and increase the exergetic efficiency.

\section{Acknowledgments}

This investigation has been partially funded by the Colombian Administrative Department of Science, Technology and InnovationCOLCIENCIAS, through the program "es tiempo de volver". Authors wish to express their acknowledgments to COLCIENCIAS and its excellent program.

\section{References}

Oliver, A., Neila, F. J., García-Santos ,A.(2010). PCM choosing and classification according to their characteristics for their application for thermal energy storage systems. Materiales de construccion, 62, 131-140.

Kocaa,A., Oztop,H.F., Koyun, T., Varol,Y. (2007). Energy and exergy analysis of a latent heat storage system with phase change material for a solar collector. Renewable Energy ,33, 567-574.

Nkwetta, D.N., Haghighat,F. (2014). Thermal energy storage with phase change material- A state of the art review. Sustainable Cities and Society, 10, 87-100.

Jafarkazemi,F., Ahmadifard,E. (2013). Energetic and exergetic evaluation of flat plate solar. Renewable Energy, 56, 55-63.

Kalogirou,S.A.(2004). Solar thermal collectors and applications. Progress in Energy and Combustion Science, 30(3), 231-295.
Li, G. (2015). Energy and exergy performance assessments for latent heat thermal energy storage systems. Renewable and Sustainable Energy Reviews, 15, 926-954.

Asbik.M., Ansari,O.,Bah,A., Zari,N., Mimet,A.,ElGhetany,H.(2016). Exergy analysis of solar desalination still combined with heat storage system using phase change material (PCM). Desalination ,381, 26-37.

Moran, M. J.,Shapiro, H. N.(Ed.). (2004). Fundamentals of Engineering Thermodynamics.(4th ed.) .Barcelona: Reverté, S.A.

Petela, R. (1964). Exergy of Heat Radiation. J. Heat Transfer, 86(2). 187-192.

Jegadheeswaran,S., Pohekar, S.D., Kousksou,T.(2010). Exergy-based performance evaluation of latent heat thermal storage system: A review. Renewable and Sustainable Energy Reviews , 14 (9), 2580-2595.

Kalogirou,S.A., Karellas,S.,Braimakis, K., Stanciu,C., Badescu,V. (2016). Exergy analysis of solar thermal collectors and processes. Progress in Energy and Combustion Science ,56, 106-137. 